\title{
The influence of internal catalyst on exhaust emission in dynamic conditions
}

\author{
Jacek Pielecha ${ }^{1, *}$, and Monika Andrych-Zalewska ${ }^{2}$ \\ ${ }^{1}$ Poznan University of Technology, Institute of Combustion Engines and Transport, Piotrowo Street 3, \\ 60-965 Poznan, Poland \\ ${ }^{2}$ Wroclaw University of Science and Technology, Faculty of Mechanical Engineering, Lukasiewicza \\ Street 5, 50-371 Wroclaw, Poland
}

\begin{abstract}
The article discusses the use of an internal catalyst, which allows to reduce the emission of harmful compounds during internal combustion engine operation. This is a type of exhaust aftertreatment system; however, its placement inside the combustion chamber, and thus closest to the combustion process, allows reducing the pollution at the source (the catalyst was sprayed on the glow plugs). This is necessary because vehicle pollution reduction is a key aspect of reducing the negative environmental impact of transport. The presented research results are a part of a wider research scheme, on the evaluation of the internal catalyst impact in various engine operating conditions - starting from static tests (on an engine dynamometer), through dynamic dynamometer tests, and ending with vehicle road tests in real driving conditions. The use of an internal catalyst during dynamic tests results in a few percent reduction in the mass of carbon monoxide, hydrocarbons, carbon dioxide and the number of particulates in the considered measurement test. It is technically possible to introduce this kind of a technical solution in most vehicles with Diesel engines, thus resulting in improved ecological properties of internal combustion engines.
\end{abstract}

\section{Introduction}

Piston combustion engines are currently a common source of drive in vehicles, machinery and equipment. Initially, such engines were used in stationary applications, but in time thanks to their many advantages, they began also being used in rail vehicles. The pursuit of obtaining ever higher power per liter from these engines, the improvement of operating parameters, reduction of weight and harmful impact on the environment are just some of the requirements currently placed on modern combustion engines. These requirements significantly affect the process of refining the engine's construction, including its individual elements and components. They are also the reason behind the constant changes in the proper operation of internal combustion engines, aimed at achieving such goals while still maintaining a low environmental impact [1]. The combustion engine's operation determines the formation of harmful exhaust components, as their primary source lies in the proper

\footnotetext{
* Corresponding author: jacek.pielecha@put.poznan.pl
} 
execution out the combustion process. Increasingly more emphasis is being placed on reducing the negative environmental impact of vehicles with combustion engines, both from legal institutions of individual countries, as well as their citizens, which forces the search for more sophisticated technical solutions for internal combustion engines [2]. These are to ensure the environmental impact reduction as well as meeting the current emission standards (including in dynamic tests and in real traffic conditions). Among these activities, those that affect the reduction of exhaust emissions from the internal combustion engine, i.e. advanced exhaust gas aftertreatment systems are most important [3]. Due to the specifics of such systems' operation, obtaining their high light-off temperature for proper operation requires placing these systems close to the engine unit. However, these systems are designed to reduce the pollutants that have already been generated in the internal combustion engine. On the other hand, one should look carefully at solutions that are technically available, and which would reduce the production of pollution at the very source - in the combustion chamber itself - placing catalysts as close to the combustion process as possible.

\section{Internal catalysts application possibilities}

The conditions in which combustion takes place should, above all, ensure that the fuel energy is fully released (full and complete combustion) fully utilizing the available air and maintaining the exhaust gas purity. The thermodynamic analysis of the engine's thermal circuit shows that the efficiency of using the heat released through combustion in a given engine is determined by the heat release location in time. The conditions for full heat release, and then its use as well as obtaining low dynamic loads of the crankshaft mechanism with possibly low noise are therefore opposed to each other and any technical solution to this problem must be resolved as a compromise. An additional factor affecting this compromise is the composition of the exhaust gases, which must now meet specific requirements [4].

In the first period (self-ignition delay), the atomized fuel stream undergoes preparation, as a result of which points of self-ignition appear in various places on the stream envelope. Oxidation during this period can be represented as a slow burning process without the occurrence of flame or pressure increase. This process is exothermic, and thus heat is released, part of which heats the fuel-air mixture, and the rest is dispersed on the combustion chamber walls. Heating the mixture accelerates reactions, which leads to further oxidation and heat release. Under certain conditions, the amount of heat released becomes equal to the amount of heat dissipated, resulting in a thermal equilibrium, which corresponds to the self-ignition temperature of the mixture. This thermal equilibrium quickly disappears as the mixture further heats up and the pressure increases, which eventually leads to the mixture self-ignition and combustion [5].

For the reaction to start, the reacting particles must collide with each other. In fact, not all collisions cause a reaction between the colliding molecules. The particles have finite velocities, so only a certain number of them causes a reaction to occur. Effective collisions were defined as only those collisions whose energy at the moment of impact is greater than the average energy determined for a given temperature. Activation energy is the surplus energy that molecules should have at the moment of impact so that they can trigger a chemical reaction and is the basic factor determining the occurring chemical processes. The smaller the activation energy, the higher the reaction rate constant and the faster the reaction [6]. To help overcome the energy barrier associated with the activation energy, more energy (e.g. heating) can be delivered to the reaction environment, or a substance (catalyst) can be used that readily reacts with the substrate (low activation energy) and the resulting compound easily converts to the end product (also low activation energy). After 
the substrates have been transformed into products, the catalyst is completely reverted to its original chemical state, thus it is sometimes stated that the catalyst is a substance that does not take part in the reaction but only facilitates it.

Based on this analysis, it can be concluded that the improvement of ecological and economic parameters of combustion engines depends primarily on the correct execution of the combustion process - depending largely on the activation energy and on the presence of a catalyst increasing the rate of chemical reactions [7,8]. Therefore, it is proposed that this internal catalyst should be used as an outer surface for selected combustion chamber elements.

\section{The aim and scope of research}

The results of pollutant emission tests presented in this article are a part of research on the evaluation of internal catalyst application in various engine operating conditions:

- cold engine start (measurement upstream and downstream of the catalytic converter),

- hot engine start (measurement upstream and downstream of the catalytic converter),

- dynamic tests,

- tests in real driving conditions.

The presented scope of pollutant emission tests was performed in dynamic tests. The measurement of pollutant concentrations $\left(\mathrm{CO}, \mathrm{HC}, \mathrm{NO}_{\mathrm{x}}, \mathrm{PN}\right.$ and $\left.\mathrm{CO}_{2}\right)$ was carried out for $1180 \mathrm{~s}$ with a simultaneous measurement of the exhaust gas flow. This allowed for the mass of pollutants emitted in the considered period of time to be determined.

The aim of the research was to determine the influence of an internal catalyst on the harmful compounds emission during dynamic tests conducted on an engine dynamometer. The scope of tests included NEDC drive tests performed on a dynamic engine dynamometer for a compression ignition engine with standard glow plugs and one using glow plugs with a catalytic coating. To properly measure the effects of an internal catalyst the pollutant concentration was measured upstream from the catalytic converter placed in the engine exhaust system.

\section{Research methodology}

The tests were carried out on the DYNOROAD $120 \mathrm{~kW}$ station by AVL that allows the recording of parameters in a wide measurement resolution range while maintaining a high sampling frequency. One of the basic functions of the device is the ability to implement a simulation algorithm in the device software, that reflect the combustion unit operation in RDE conditions. The influence of drive system components, construction parameters of the modelled vehicle such as gear ratios, drive train losses, mass, air resistance coefficient of the vehicle due to its cross section, clutch performance, inertia and generated drive axle friction are all taken into account. An additional feature is the ability to condition the operating fluids and the fuel supply system. The stand, when fully equipped, allows archiving a large number of parameters related to the engine operation, as well as related systems. The method of data acquisition, range and sampling frequency is defined by the operator. The test stand can be supplemented with additional signals from, among others, sensors enabling measurements of physical quantities and electrical signals, but most importantly with the equipment enabling the exhaust gases analysis. Such an approach to a defined problem makes it possible to carry out research in a wide range of operating conditions.

The basic executive element for performing the tasks at the test stand (Fig. 1) is a threephase, asynchronous electrical machine with a cage construction (Tab. 1). It can receive 
a maximum power of less than $120 \mathrm{~kW}$. During operation, the combustion engine used generates mechanical work which is converted into electricity in the dynamometer, which after voltage and frequency transformation is transferred to the external network. The ISAC 400 software interface installed at the stand enables defining a test cycle including the chassis (NEDC) and engine tests (WHSC), but most importantly, it enables customization of the individual algorithm using the vehicle speed change as a function of time $f=V(t)$ and the change of the road slope in time $f=\alpha(t)$. Nevertheless, in order to determine the physical properties of the simulated vehicle, taking into account the drive transmission parameters and components of the vehicle structure, requires the implementation of data obtained experimentally on the real model or made available by the vehicle manufacturer (Tab. 2).

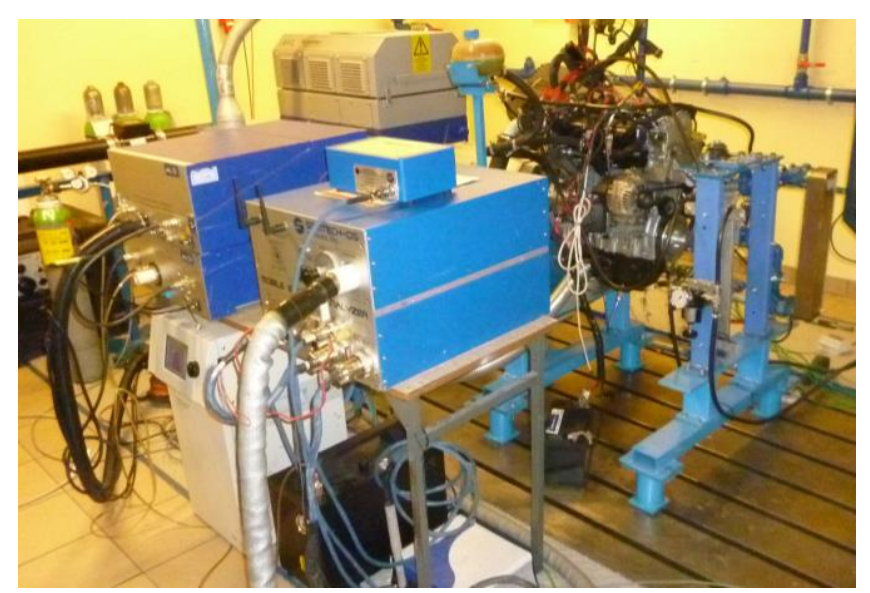

Fig. 1. Test stand used in the research.

Table 1. Dynamic brake technical data.

\begin{tabular}{|c|c|}
\hline Voltage & $3 \times 500 \mathrm{~V}$ \\
\hline Frequency & $267 \mathrm{~Hz}$ \\
\hline Maximum current & $159 \mathrm{~A}$ \\
\hline Power & $120 \mathrm{~kW}$ \\
\hline Maximum torque & $509 \mathrm{~N} \cdot \mathrm{m}$ \\
\hline Engine speed range & $0-8000 \mathrm{rpm}$ \\
\hline Power use & $6400 \mathrm{~W}$ \\
\hline
\end{tabular}

Table 2. Drive unit operational parameters in the simulated vehicle.

\begin{tabular}{|c|c|}
\hline Ignition type & Diesel \\
\hline Displacement & $1248 \mathrm{~cm}^{3}$ \\
\hline Cylinder number & 4 \\
\hline Maximum power & $66 \mathrm{~kW}$ at $4000 \mathrm{rpm}$ \\
\hline Maximum torque & $200 \mathrm{Nm}$ at $1750 \mathrm{rpm}$ \\
\hline Compression ratio & 18.0 \\
\hline
\end{tabular}

The application of ceramics onto glow plugs (done at Pratt \& Whitney Rzeszów SA) was carried out according to the following sequence: 
1. The sprayed element was first subjected to abrasive blasting using electro-corundum with a grain size of approx. $0.6 \mu \mathrm{m}$. The time between sandblasting and coating was less than 2-4 h, the surfaces were washed with a solvent.

2. The spray coating process was carried out in two stages:

- application of a base layer with a thickness of about $0.1 \mathrm{~mm}$, using a nickel based powder for which the grain size was less than $100 \mu \mathrm{m}$, and hardness in the molten state was about 20 HRC;

- applying ceramic layer with a thickness of about $0.1 \mathrm{~mm}$, a $\mathrm{ZrO}_{2}$ powder was used, stabilized with yttrium (20\% yttrium), with a grain size in the range of $40-60 \mu \mathrm{m}$; from a distance of about $100 \mathrm{~mm}$, onto an element at $200^{\circ} \mathrm{C}$.

3. The spraying process was carried out using a plasma torch; the plasma power was about $15 \mathrm{~kW}$ for the base and $30 \mathrm{~kW}$ for the ceramic layer.

4. The surface of the layers was not sanded.

The layers obtained on glow plugs are shown in Figure 2.

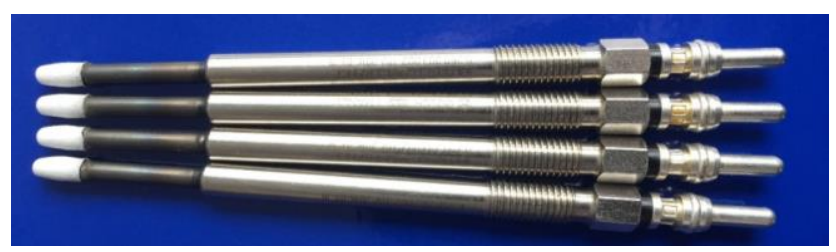

Fig. 2. Glow plugs with the ceramic coating layer.

\section{Research results}

During the pollutant emission testing in cold engine starting conditions, the engine operating parameters (engine speed and load) and thermodynamic parameters (flow rate and flue gas temperature) were recorded. Similar values of these parameters (Fig. 3) allow for pollutant concentration values comparison and the calculated mass of exhaust components when using standard glow plugs and catalyst coated plugs.

The exhaust compounds concentration measurements were made to determine the mass differences of the: carbon monoxide, hydrocarbons, nitrogen oxides, the number of solid particles and carbon dioxide emitted during the NEDC test using the standard and the catalyst coated glow plugs.

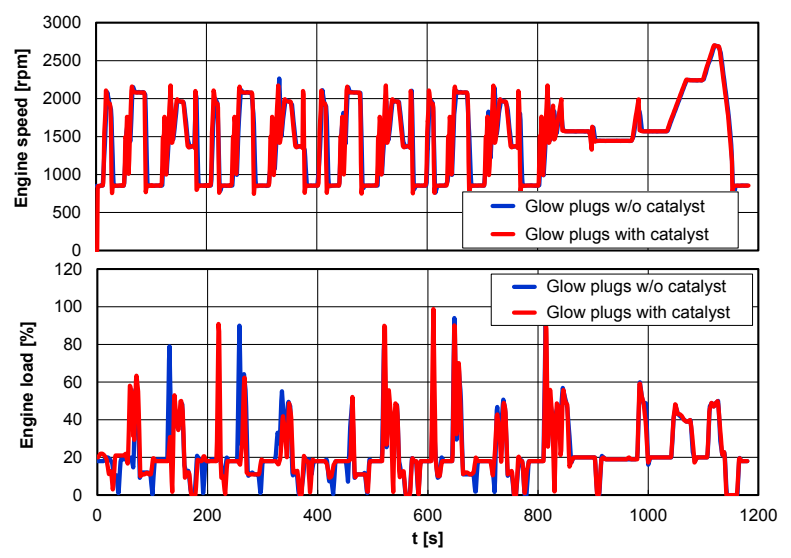

Fig. 3. Comparison of engine operating parameters: engine speed and load during the NEDC test of the Diesel engine with the use of standard and catalyst coated glow plugs. 
For the carbon monoxide concentration measurement, a rapid increase in the concentration value was observed immediately after engine start (up to $1000 \mathrm{ppm}$ ), followed by a steady reduction down to $400 \mathrm{ppm}$ (in several seconds after starting); values of around $700 \mathrm{ppm}$ were observed for increased vehicle travel speed. The differences in concentration values were small, however, the conversion of the concentration value into the emission intensity and then the sum of these values shows the reduction of the emitted carbon monoxide mass during the engine start-up and heating stages (Fig. 4).
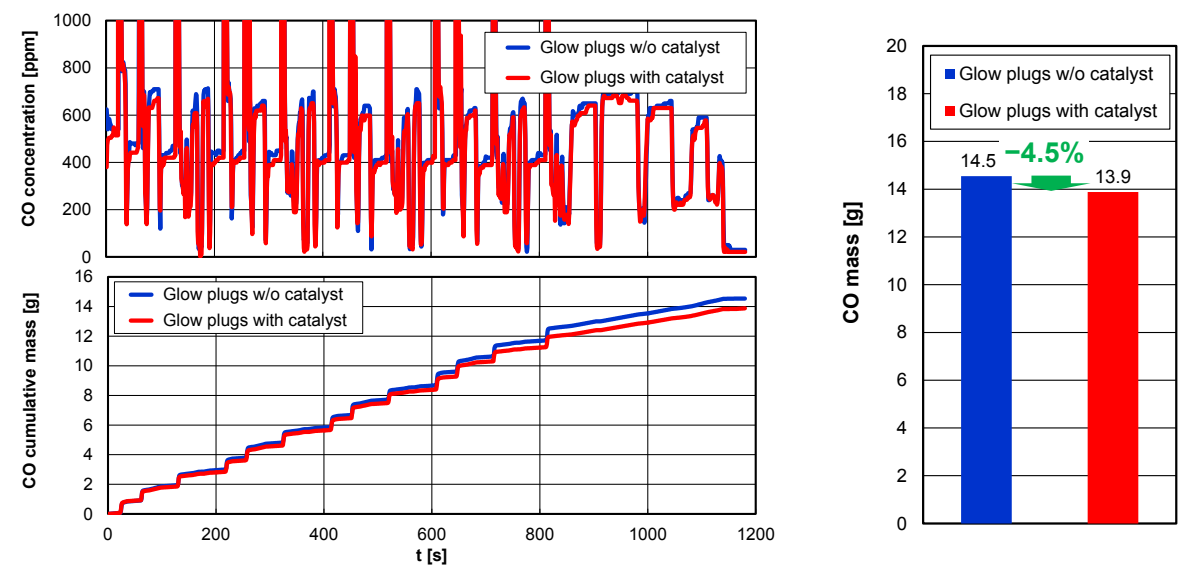

Fig. 4. Carbon monoxide concentration and mass comparison in the NEDC test of the Diesel engine with the use of standard and catalyst coated glow plugs.

A similar result was obtained for hydrocarbon concentration measurements. However, in this case, greater differences in concentration values were obtained, resulting in the emission of a smaller mass of hydrocarbons when using the catalyst coated glow plugs (Fig. 5).

The final mass values of these pollutants, determined for the whole test duration (1180 s), show the differences in engine pollutant emissions during the entire NEDC test when using standard and catalyst coated glow plugs. In the case of the coated plugs, the obtained results relative to the standard glow plugs were as follows:

- about 4,5-percent lower mass of carbon monoxide emitted,

- about 5-percent lower mass of hydrocarbons emitted,

in the entire NEDC test.
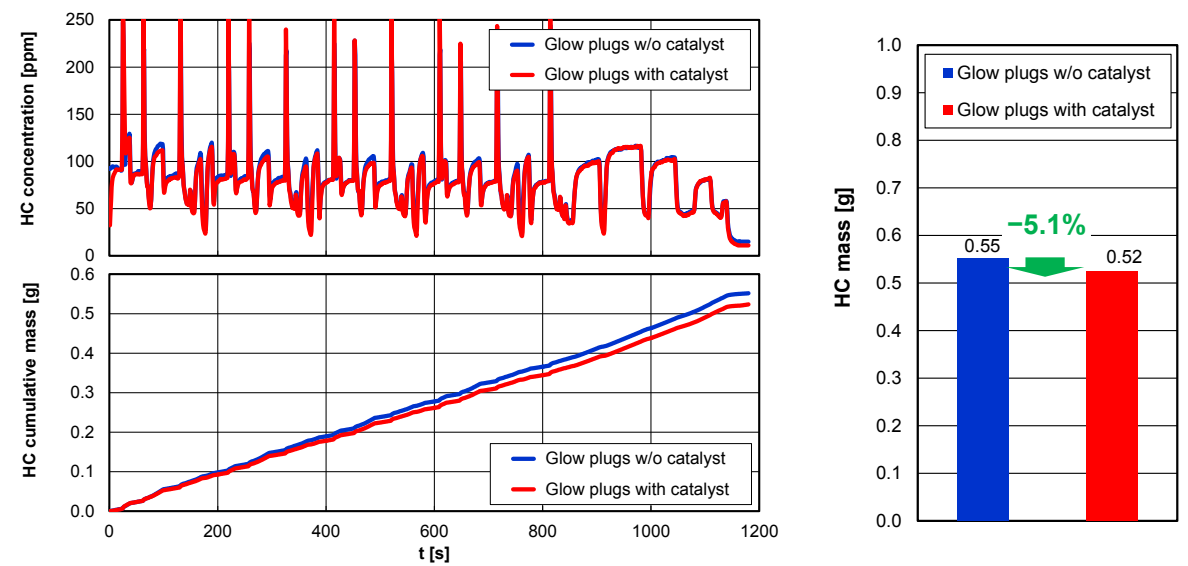

Fig. 5. Hydrocarbons concentration and mass comparison in the NEDC test of the Diesel engine with the use of standard and catalyst coated glow plugs. 
The opposite result was obtained in the case of nitrogen oxides: higher concentration of this compound was observed in the initial measurement period for the coated plugs. This result - expressed by the mass of pollution emitted - continued through the entire test duration (Fig. 6). In the case of the particle number (Fig. 7), the observed emission change was similar to the results of previous compounds - as for carbon monoxide and hydrocarbons. In total, a $9 \%$ increase in the mass of emitted nitrogen oxides and an about $11 \%$ decrease in the number of emitted particles was observed.
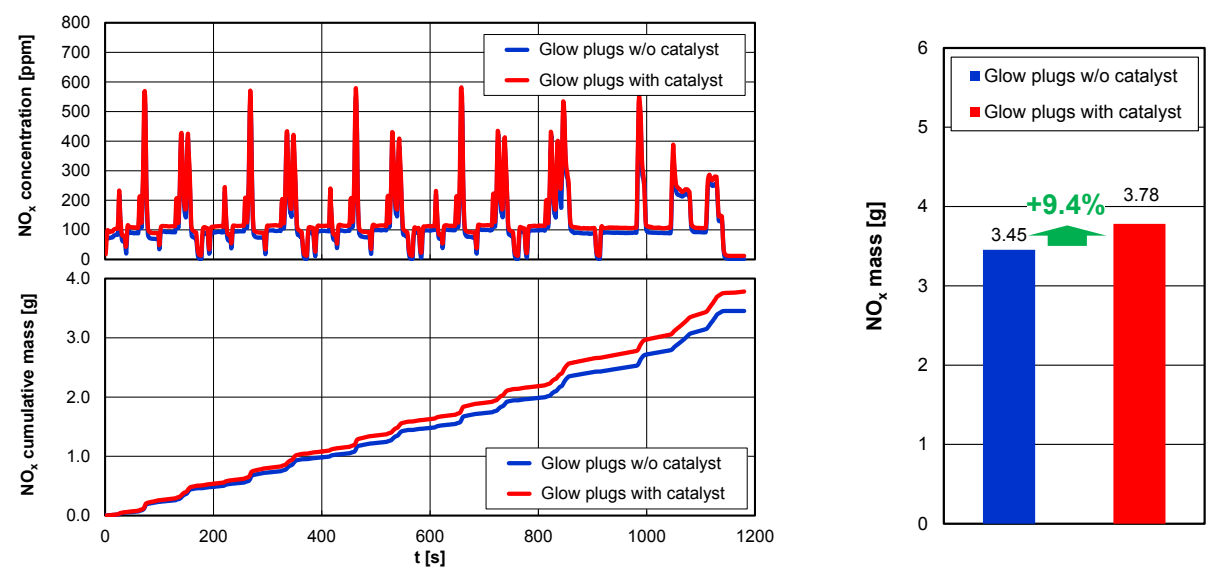

Fig. 6. Emitted nitrogen oxides concentration and mass values comparison in the NEDC test of the Diesel engine using standard and catalyst coated glow plugs.
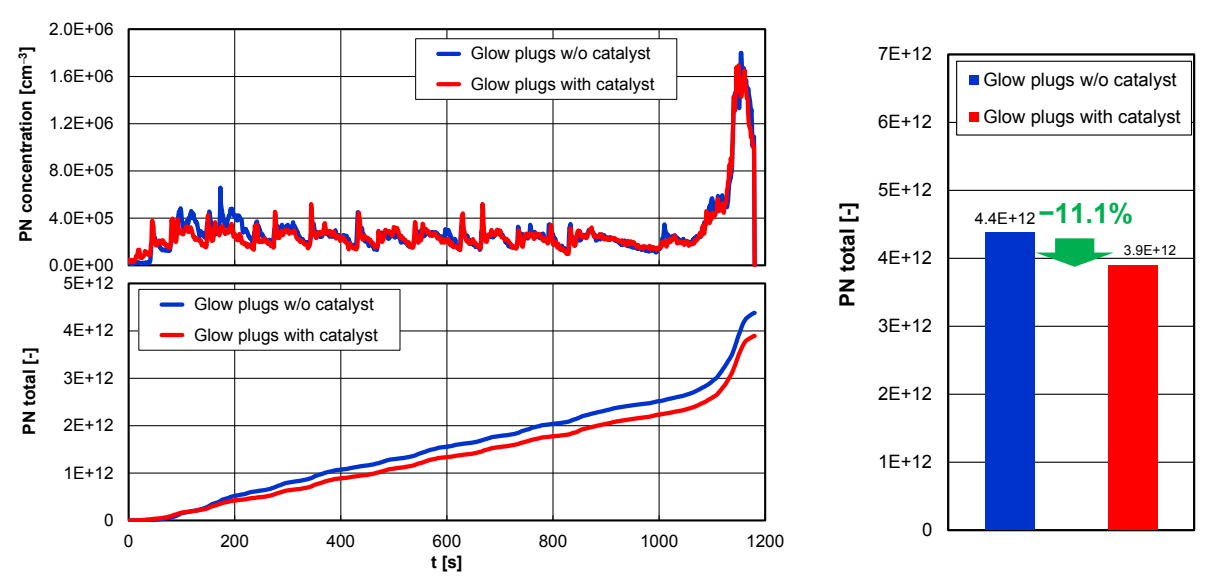

Fig. 7. Comparison of numerical concentration and the number of particles emitted in the NEDC test of the Diesel engine using standard and catalyst coated glow plugs.

For comparison, in order to estimate the fuel consumption reduction, the change in the carbon dioxide mass emitted throughout the entire measurement period was investigated. When using the catalyst coated plugs, a reduction in the carbon dioxide concentration was obtained, which at the same exhaust gas flow rate, resulted in a reduction in the emitted mass of this compound in the NEDC test. After $1180 \mathrm{~s}$ from the NEDC test start while using modified glow plugs, mass of the emitted carbon dioxide was approximately $4 \%$ lower (Fig. 8). 

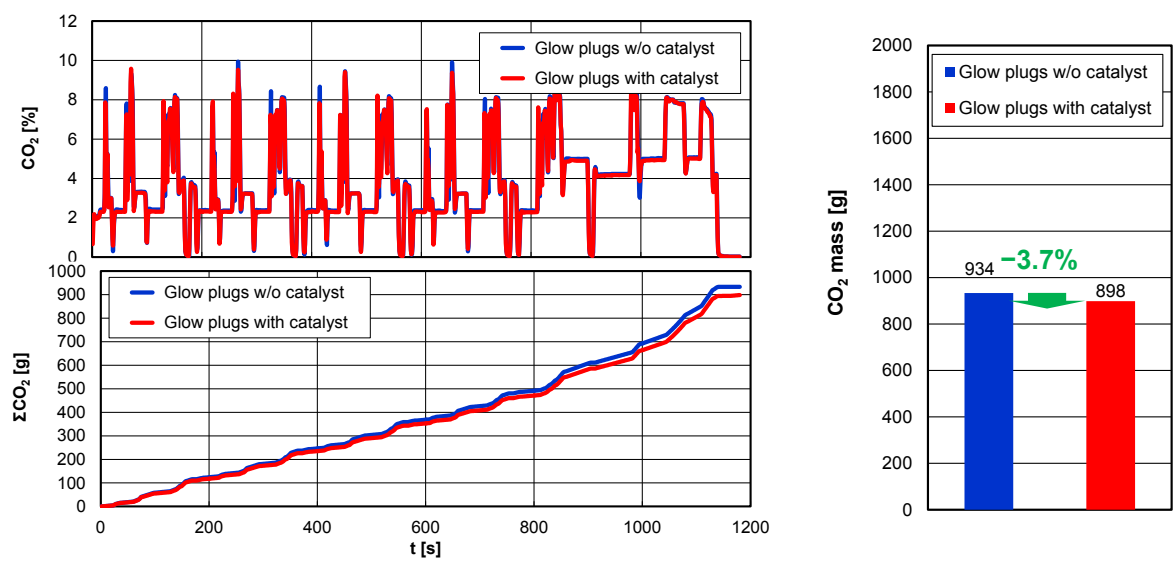

Fig. 8. Emitted carbon dioxide concentration and mass comparison in the NEDC test of the Diesel engine using standard and catalyst coated glow plugs.

\section{Conclusions}

The conducted analysis of pollutant emission tests shows that placing an internal catalyst in the combustion chamber of the CI engine has positive ecological effects in the NEDC test conditions. The following results were obtained in the comparative tests of this stage of the engine operation when using standard and catalyst coated glow plugs: about 4.5-percent lower carbon monoxide mass, about 5-percent lower hydrocarbons mass, about 9-percent higher nitrogen oxides mass, about 11-percent lower particle number, about 4-percent lower carbon dioxide mass (which translates into a $4 \%$ reduction in fuel consumption).

The obtained values of reducing the mass of emitted pollutants through the use of modified glow plugs are a reliable indicator of the possibility of limiting these pollutants emission immediately after their creation, within the combustion chamber.

The study presented in this article was performed within the statutory research (contract No. 05/52/DSPB/0260).

\section{References}

1. J. Merkisz, J. Pielecha, Nanoparticle Emissions from Combustion Engines, 8 (2015)

2. S. Kruczynski, M. Slezak, W. Gis, P. Orlinski, Eksploat. Niezawodn. 18, 343-347 (2016)

3. P. Lijewski, J. Merkisz, P. Fuc, A. Ziolkowski, L. Rymaniak, W. Kusiak, Eur. J. Forest. Res. 136, 153-160 (2017)

4. P. Soltic, C. Bach, Catalytic piston coating (Conference Gas Powered Vehicles, Berlin, 2010)

5. K. Karuppasamy, M.P. Mageshkumar, T.N. Manikandan, J. Naga Arjun, T. Senthilkumar, B. Kumaragurubaran, M. Chandrasekar, ARPN J. Sci. Technol. 3 (2013)

6. T. Hejwowski, Vacuum, 2 (2012)

7. I. Pielecha, M. Skowron, A. Mazanek, Eksploat. Niezawodn. 20, 83-89 (2018)

8. L. Kapusta, I. Pielecha, K. Wislocki, A. Teodorczyk, J Therm. Anal. Calorim. 123, 819-828 (2016) 